\title{
Hints for the user of COMECON FOREIGN TRADE DATA 1984:
}

The information assembled in this pocket-book is arranged, as a rule, in groups of tables, the first table quoting absolute figures and references to the source(s) used. From these, subsequent tables showing 'average annual growth rates' and 'percentages of totals' are usually derived, the first table in the group being used as the main source.

More than 50 titles - statistical yearbooks and periodicals from CMEA countries, from selected Western countries and of international organisations - are listed in the sources register.

Source references do not refer to the particular volume and page of the specific yearbook or to the specific issue of the periodical quoted; a citation reading, e.g. 'Source: Sl', stands for the source 'Vneshnyaya torgovlya'. Sources and the codes designating them are listed in the sources register.

Noughts before the decimal point were dispensed with. What might customarily be written ' 0.8 ' will appear in these tables thus: .8 ; and accordingly, 'minus $0.8^{\prime}$ ' will apear thus: -.8 .

Other symbols and their meanings:

$$
\begin{array}{ll}
\text { no in formation available } & \text { magnitude equalling zero } \\
\text { - } & \text { or } .0 \text { or }-.0 \quad \text { value (or quantity) rounded off to zero }
\end{array}
$$

-.0 is to be interpreted as a negative quantity but so small that it was rounded off to zero (e.g. -0.05 ).

At the beginning of each chapter definitions are given of the most important concepts used for the statistics. 